\title{
Erratum to: Porous Structures from Fibrous Proteins for Biomedical Applications
}

\author{
Helan Xu and Yiqi Yang
}

\section{Erratum to:}

Chapter 7 in: Y. Yang et al. (eds.), Porous Lightweight Composites Reinforced with Fibrous Structures,

https://doi.org/10.1007/978-3-662-53804-3_7

The authors for Chapter 7 are not correct. There should be only two authors, Helan

$\mathrm{Xu}$ as the first author and Yiqi Yang as the corresponding author, for this chapter.

The updated online version of this chapter can be found at https://doi.org/10.1007/978-3-662-53804-3_7

$\mathrm{H} . \mathrm{Xu} \cdot \mathrm{Y}$. Yang $(\bowtie)$

Department of Textiles, Merchandising and Fashion Design, University of Nebraska-Lincoln, Lincoln, NE, USA

e-mail: hxu14@unl.edu; yyang2@unl.edu 